\title{
Metallization of Extruded Briquettes (BREX) in Midrex Process
}

\author{
Aitber Bizhanov ${ }^{1, *}$ (1) and Tatyana Malysheva ${ }^{2}$ \\ 1 J.C. Steele\&Sons, Inc., 710 South Mulberry Street, Statesville, NC 28677, USA \\ 2 Department of Extraction and Recycling of Ferrous Metals, National University of Science and Technology, \\ "MISIS" (MISIS), Leninskiy Prospect 4, 119991 Moscow, Russia; igivgu@mail.ru \\ * Correspondence: abizhanov@jcsteele.com; Tel.: +7-916-842-9111
}

Received: 12 February 2017; Accepted: 4 July 2017; Published: 7 July 2017

\begin{abstract}
The results of the full-scale testing of the Extruded Briquettes (BREX) as the charge components of the industrial Midrex reactor are discussed. The influence of the type of binder on the degree of metallization of BREX is analyzed. Magnesium sulfate-based binder helps to reach highest metallization degree of BREX. Mineralogical study shows the difference in the iron-silicate phase's development as well as in the porosity change during metallization depending on the binder used.
\end{abstract}

Keywords: extrusion briquette (BREX); stiff vacuum extrusion (SVE); metallization; porosity; silicates; electric arc furnaces (EAF) dust; direct reduction iron (DRI) sludge; Midrex process

\section{Introduction}

The process of mini steel mills using oxidized pellets as a feedstock includes production of metallized pellets, which are used further for the production of direct reduction iron (DRI), production of steel in electric arc furnaces (EAF) and its continuous casting and rolling. Such companies are importing annually large amounts of the iron ore pellets for DRI production and during the transportation, stockpiling, charging of the pellets to the metallization reactors and discharging of the metallized pellets dozens of thousand tons of fine iron-containing materials are being generated. Pellets fines and DRI sludge are usually dumped in piles and EAF dust and mill scale are sold to a third-party. Results of the preliminary analysis indicate that the recycling of such materials in the form of briquettes would help to produce additional quantities of steel and release significant area occupied by dumped wastes. Utilization of these wastes would generate additional revenues, surpassing revenue from direct sales of wastes.

Previously we have studied the possibility to apply Stiff Vacuum Extrusion (SVE) for agglomeration of the natural and anthropogenic fine materials generated during ironmaking and Ferro Alloys production [1-3]. The main aims of the present study are: (a) to develop cost-effective procedure for recycling of the oxide materials, wastes of DRI production and EAF dusts, in order to improve the environmental situation in the enterprise; (b) to choose the efficient binder which will allow to achieve the highest degrees of briquettes metallization.

The present paper considers the possibility to use SVE to agglomerate the above-mentioned materials with the metallurgical quality suitable for use as a charge component in the DRI reactors.

\section{Materials and Methods}

Full-scale testing of the experimental Extruded Briquettes (brex) behavior took place in the industrial Midrex reactor. Experimental brex were placed inside deformable steel packages permeable for the reducing gas (Figure 1). Such input method allows to adequately simulate brex behavior in real 
conditions of the reactor, including mechanical pressure of the surrounding traditional charge. At the end of the process, these packages were drawn out of the reactor allowing to visually determine the condition of the reduced brex and to explore their chemical composition and properties.

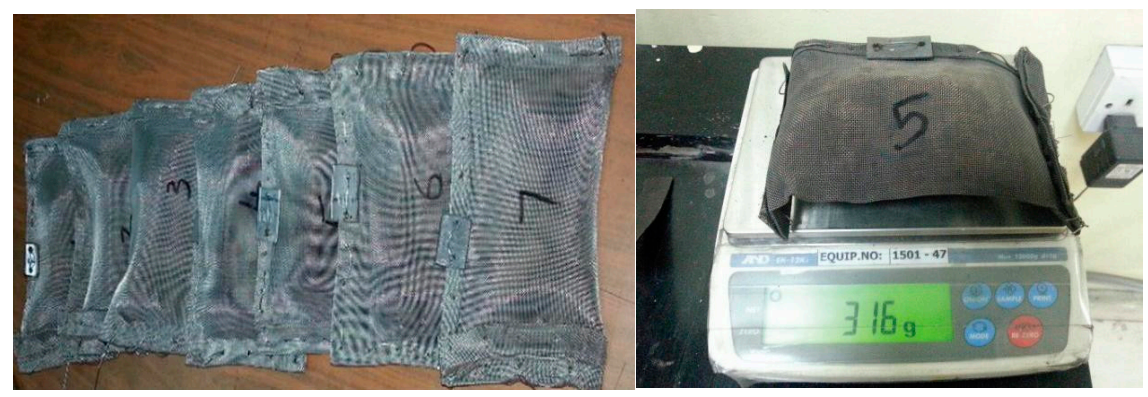

Figure 1. Deformable steel packages for feeding of Extruded Briquettes (brex) into Midrex reactor.

\subsection{Raw Materials}

Prepared mix of pellets fines (52.6\%); metallized sludge of DRI production (26.4\%), mill scale $(15.8 \%)$ and EAF dust (5.2\%) has been used. Particle size analyses were performed using wet screens from mesh $4(4.75 \mathrm{~mm})$ to mesh $325(45 \mu \mathrm{m})$. Particle size distribution of the mix before and after its grinding by the lab-scale roll-crusher is given in Figure 2 .

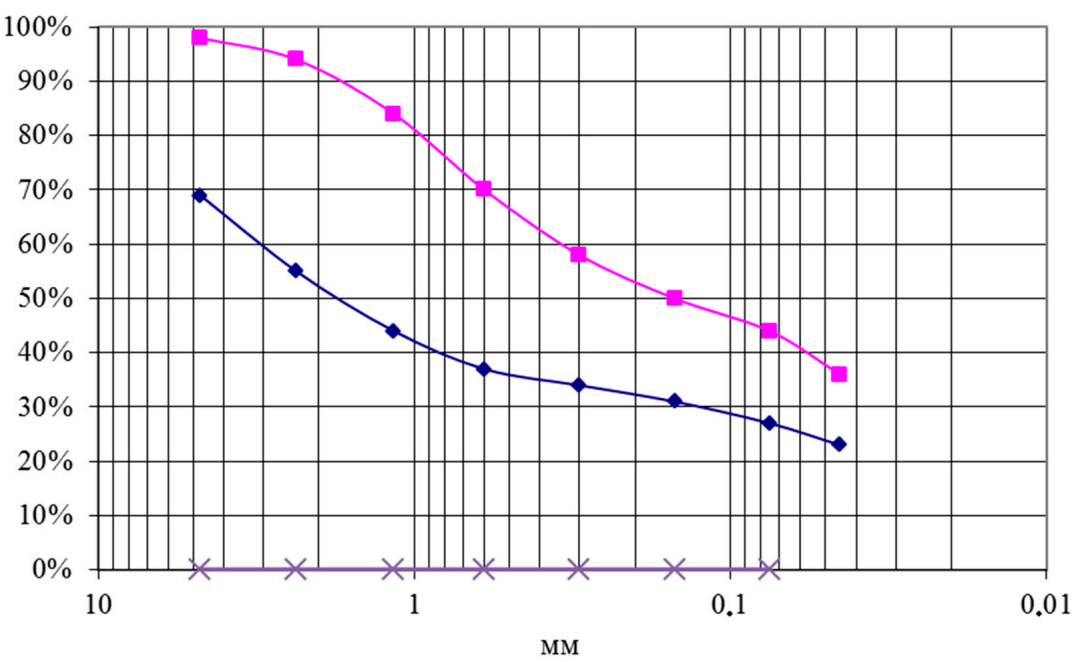

Figure 2. Particle size distribution of the briquetted charge. Lower-original mix; upper-after grinding.

Chemical composition of the mix components is given in Table 1.

Table 1. Chemical composition of the mix components.

\begin{tabular}{ccccc}
\hline Chemical Compounds & Pellets Fine & Mill Scale & DRI Sludge & EAF Dust \\
\hline $\mathrm{Fe}_{\text {tot }}$ & 65.00 & 70.0 & 66.2 & 29.68 \\
$\mathrm{SiO}_{2}$ & 2.50 & 1.00 & 2.14 & 4.25 \\
$\mathrm{CaO}$ & 1.30 & 0.15 & 4.38 & 19.74 \\
$\mathrm{MgO}$ & 0.75 & 0.10 & 0.69 & 24.27 \\
$\mathrm{Al}_{2} \mathrm{O}_{3}$ & 0.95 & 0.25 & 0.83 & 1.32 \\
$\mathrm{MnO}$ & 0.10 & 1.20 & 0.16 & 0.96 \\
$\mathrm{~S}$ & 0.015 & 0.015 & 0.01 & 0.13 \\
$\mathrm{Na}_{2} \mathrm{O}+\mathrm{K}_{2}$ & 0.034 & - & 0.33 & 1.42 \\
\hline
\end{tabular}




\subsection{Experimental Brex Production}

All test samples were extruded using a $25 \mathrm{~mm}$ round pelletizing die. A Hobart laboratory mixer was used to simulate the mixing with water and pugging of the ground feed material in the open tub of the pug sealer. The laboratory extruder simulates the processing of the material through the sealing auger and die, into the vacuum chamber, and then final extrusion.

The laboratory extruder consists of two chambers with a sealing die between. The rear chamber is fitted with a 3-inch diameter sealing auger that pushes material through the sealing die. The second chamber can be subjected to vacuum. It is also fitted with a 3-inch diameter auger that extrudes material through a pelletizing die. A PC-based data system monitors and records extrusion data. All mixes were extruded immediately after mixing. Three types of the experimental brex were produced with the compositions given in Table 2.

Table 2. Experimental brex compositions, \%.

\begin{tabular}{cccc}
\hline Charge Component & Brex \#1 & Brex \#2 & Brex \#3 \\
\hline Pellets fines & 50.0 & 50.0 & 50.0 \\
Sludge & 25.0 & 25.0 & 25.0 \\
Mill scale & 15.0 & 15.0 & 15.0 \\
EAF dust & 5.0 & 4.75 & 5.0 \\
Slaked lime & 5.0 & - & - \\
Portland cement & - & 5.0 & - \\
Magnesium binder & - & - & 5.0 \\
Bentonite & - & 0.25 & - \\
\hline
\end{tabular}

Magnesium sulfate-based binder has been composed based on the heptahydrate of the magnesium sulphate $\left(\mathrm{MgSO}_{4} \cdot 7 \mathrm{H}_{2} \mathrm{O}\right)$. Binding properties of the magnesium sulphate were first described by Zhuravlev et al. [4]. The change in form that occurs when a dehydrated inorganic salt is converted to the hydrated crystal form is the basis for the recommendation that a partially dehydrated magnesium sulfate be used industrially as a binding material. Setting begins in $3 \mathrm{~min}$ and is complete in $6 \mathrm{~min}$. Chemical composition of the brex is given in Table 3.

Table 3. Chemical composition of experimental brex before reduction, $\%$.

\begin{tabular}{cccc}
\hline Elements and Oxides & Brex \#1 & Brex \#2 & Brex \#3 \\
\hline $\mathrm{Fe}_{t}$ & 62.47 & 61.30 & 62.61 \\
$\mathrm{C}$ & 1.49 & 1.40 & 1.05 \\
$\mathrm{CaO}$ & 9.24 & 8.41 & 4.30 \\
$\mathrm{MgO}$ & 3.61 & 3.07 & 6.24 \\
$\mathrm{SiO}$ & 2.45 & 4.91 & 2.76 \\
$\mathrm{Al}_{2} \mathrm{O}_{3}$ & 1.29 & 1.81 & 0.99 \\
$\mathrm{TiO}_{2}$ & 0.10 & 0.12 & 0.12 \\
$\mathrm{~V}_{2} \mathrm{O}_{5}$ & 0.076 & 0.07 & 0.08 \\
$\mathrm{MnO}$ & 0.34 & 0.36 & 0.35 \\
$\mathrm{P}_{2} \mathrm{O}_{5}$ & 0.07 & 0.09 & 0.06 \\
$\mathrm{~S}$ & 0.08 & 0.08 & 0.50 \\
$\mathrm{Na}_{2} \mathrm{O}+\mathrm{K}_{2} \mathrm{O}$ & 0.19 & 0.93 & 0.83 \\
$\mathrm{Cl}$ & 0.04 & 0.03 & 0.02 \\
$\mathrm{ZnO}$ & 0.36 & 0.40 & 0.35 \\
\hline
\end{tabular}

\subsection{Testing of the Brex Physical Properties}

A calibrated electronic scale with density measuring attachment was used to determine brex density. A compression tester was used for sample strength measurements, tensile splitting strength has been measured in accordance with ASTM (American Society for Testing and Materials) C1006-07, 
Paragraph 7.1. Porosity has been measured in accordance with DIN (Deutsches Institut für Normung) 51056. Moisture content was measured using a moisture balance. The physical-mechanical properties of the raw brex are given in Table 4.

Table 4. Physical-mechanical properties of raw brex.

\begin{tabular}{cccc}
\hline Property & Brex \#1 & Brex \#2 & Brex \#3 \\
\hline Density, g/cm ${ }^{3}$ & 3.5 & 3.48 & 3.66 \\
Compressive strength, $\mathrm{N} / \mathrm{mm}^{2}$ & 4.8 & 11.1 & 4.4 \\
Tensile splitting strength, $\mathrm{N} / \mathrm{mm}^{2}$ & 1.5 & 1.4 & 1.2 \\
Porosity & 29.7 & 24.7 & 25.1 \\
Moisture content, $\%$ & 8.4 & 8.4 & 8.6 \\
\hline
\end{tabular}

\section{Results and Discussion}

Experimental brex of the above compositions were placed into the deformable and gas-permeable steel packages (each type of brex was placed in a separate package) and these packages were added to the traditional charge of the Midrex reactor. The tests were conducted at night shift from midnight to 8:00 a.m. The reducing gas temperature was around $900{ }^{\circ} \mathrm{C}$, fresh water consumption was $248 \mathrm{~m}^{3}$, natural gas $-222,600 \mathrm{~nm}^{3}$, oxygen $-10,676 \mathrm{~m}^{3}$, and power-73,000 $\mathrm{kWh}$. At the end of the process, the packages have been removed from the reactor due to the presence of so-called cold discharge (discharge temperature $40{ }^{\circ} \mathrm{C}$ ) thus allowing to visually determine the state of the reduced brex (Figure 3 ) and to examine their chemical composition and properties.

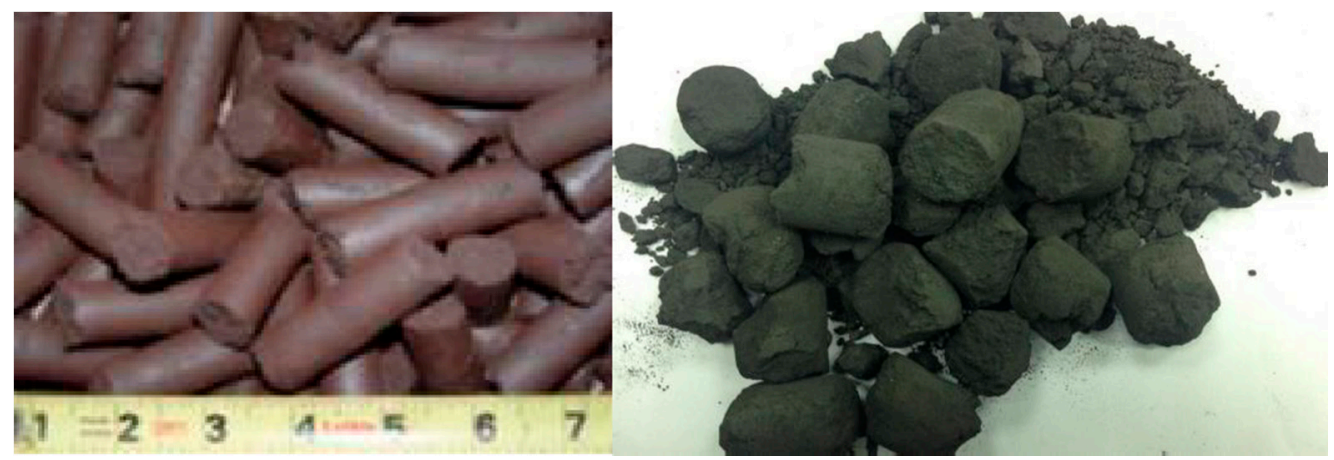

(a)

(b)

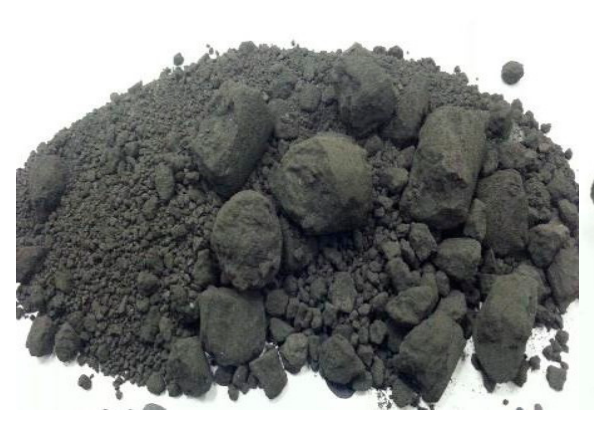

(c)

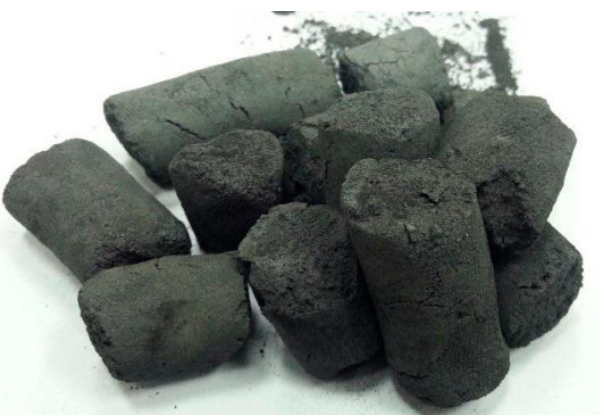

(d)

Figure 3. Raw brex (a) and reduced brex after extraction from the steel packages (b) brex \#1, (c) brex \#2, (d) brex \#3.

It can be observed that brex with the magnesium sulfate-based binder demonstrated the highest integrity. The cement-bonded brex demonstrated the largest degree of the fines generation. Brex on lime binders were destroyed in a markedly lesser extent. 
Mechanical strength values of the reduced and non-destroyed brex were defined in the splitting tensile testing $\left(0.4 \mathrm{~N} / \mathrm{mm}^{2}\right.$ for brex lime-bonded brex and $1.2 \mathrm{~N} / \mathrm{mm}^{2}$ for brex with magnesium sulfate-based binder). The strength of the brex with magnesium sulfate binder has not changed compared to its original value (Table 4). Thus, the brex with lowest values of the cold mechanical strength showed highest values of the hot strength. Respectively, the brex with the magnesium sulfate-based binder also showed the highest reducibility. Decrease in the reducibility of the limeand cement-bonded brex is related with the decrease in the permeability of the steel packages after the particles of the generated fines have blocked the holes. The chemical composition of the reduced brex and their degrees of metallization are presented in Table 5. One can see serious discrepancy in total iron contents in reduced brex. This, in turn, comes from difference in metallic iron contents. The reason for this is related with different hot strength levels of the brex and with mentioned blocking of the holes by fines of partially disintegrated brex (\#1 and \#2), which prevents income of reducing gas.

Table 5. Chemical composition and metallization of the reduced brex.

\begin{tabular}{cccc}
\hline Elements and Oxides & Brex \#1 & Brex \#2 & Brex \#3 \\
\hline $\mathrm{Fe}_{\mathrm{t}}$ & 74.86 & 69.02 & 86.86 \\
$\mathrm{Fe}_{\text {met }}$ & 49.11 & 18.66 & 84.00 \\
Metallization, $\%$ & 65.60 & 26.96 & 96.71 \\
$\mathrm{C}$ & 1.75 & 0.89 & 1.02 \\
$\mathrm{CaO}$ & 9.11 & 6.71 & 5.07 \\
$\mathrm{MgO}$ & 2.93 & 2.24 & 7.81 \\
$\mathrm{SiO}_{2}$ & 3.41 & 4.35 & 4.04 \\
$\mathrm{Al}_{2} \mathrm{O}_{3}$ & 1.47 & 2.13 \\
$\mathrm{TiO}_{2}$ & 0.11 & 0.12 & 0.12 \\
$\mathrm{~V}_{2} \mathrm{O}_{5}$ & 0.08 & 0.07 \\
$\mathrm{MnO}$ & 0.07 & 0.43 & 0.39 \\
$\mathrm{P}_{2} \mathrm{O}_{5}$ & 0.34 & 0.07 & 0.01 \\
$\mathrm{~S}$ & 0.08 & 0.09 & 0.26 \\
$\mathrm{Na}_{2} \mathrm{O}+\mathrm{K}_{2} \mathrm{O}$ & 0.03 & 0.51 & 0.74 \\
$\mathrm{Cl}$ & 0.48 & 0.01 & - \\
$\mathrm{ZnO}$ & 0.09 & 0.30 & 0.05 \\
\hline
\end{tabular}

The Midrex reactor, which has been used for full-scale testing, produces DRI that has the following guaranteed parameters: degree of metallization of $94 \%$, total iron content- $91 \%$, metallic iron content $-85 \%$, carbon content- $1.3 \%$, sulfur $-0.005 \%$. It follows from the testing results that the brex with magnesium sulfate-based binder have reached a higher degree of metallization $(96.71 \%)$, almost the same level of metallic iron and carbon content, but smaller than in DRI content of total iron. The sulphur content is significantly higher in this brex. This is evidently a limiting factor for the utilization of brex with magnesium sulfate-based binder in Midrex reactors. Sulphur will partially go to the flue-gas and in, the absence of the flue-gas desulfurization, it could spoil the quality of the catalyst of reformer. Lime-bonded brex has much lower sulphur content.

\subsection{Mineralogical Study of the Reduced Brex}

The structure of the reduced samples of brex has been studied by the methods of light microscopy using the "Nikon" equipment (polarized microscope ECLIPSE LV100 POL equipped with a digital photomicrography system DS-5M-L1) (Nikon, Tokyo, Japan). Analysis of mineral phases in polished sections of briquettes was conducted by MLA 650 (FEI Company, Hillsboro, OR, USA), including scanning electron microscope FEI Quanta 650 SEM. The main mineral phases were determined by diffraction analysis using analytical complex ARL 9900 Workstation IP3600 (combined X-ray fluorescence spectrometer) (Thermo Fisher Scientific, Waltham, MA, USA). Reduced brex with magnesium sulfate-based binder and retained integrity samples of the reduced brex with lime and cement binders were tested. 
Fines of pellets with low basicity $\left(\mathrm{CaO} / \mathrm{SiO}_{2}=0.3-0.5\right)$ are represented by the fragments of different mineral composition: cores in the form of residual magnetite with glass phase and shells consisting of splices of Hematite with calcium ferrites. Mill scale has magnetite composition-solid solution ( $\mathrm{Fe}, \mathrm{Mn}) \mathrm{O} \cdot \mathrm{Fe}_{2} \mathrm{O}_{3}$. A special role in the composition of the brex is played by EAF dust, which consists of the main melt generating components: $\mathrm{CaO}, \mathrm{MgO}, \mathrm{MnO}, \mathrm{SiO}_{2}$ and $\mathrm{Na}_{2} \mathrm{O}$.

\subsubsection{Mineralogical Analysis of the Reduced Cement-Bonded Brex}

In the reduced and non-destroyed cement-bonded brex, iron is represented by partly recovered iron containing minerals of pellets fines and mill scale.

Previously, we have tested the cement-bonded brex in rigid non-deformable baskets preventing the brex mechanical destruction [5]. The appearance of rigid baskets and reduced brex after their extraction from baskets is shown in Figure 4. Metallization of such brex after extraction from the reactor was equal to $94.21 \%$. In the absence of an external mechanical load, the surface of cement-bonded brex has been cracked. It is well known that the presence of cement is essential for swelling to take place, but beyond 4 weight percent the increase in cement content again leads to a decline in swelling. Tendency to swell may be decreased either by replacing cement with some other binder or by increasing the cement content to more than 10 weight percent [6]. Such tendency to swell explains the weakness of the cement-bonded brex during their reduction in the deformable steel packages. Further testing with the amount of the cement binder larger than $10 \%$ might be required.

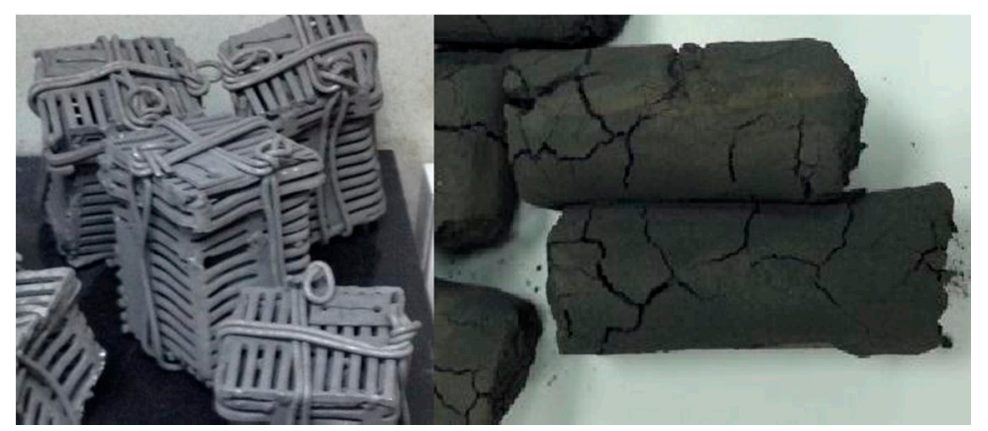

Figure 4. Rigid baskets for brex and the reduced cement-bonded brex after their extraction.

In the major body of the cement-bonded brex extracted from the steel mesh packages there are the areas with the phases close by composition to the binary metasilicates $2 \mathrm{Na}_{2} \mathrm{O} \cdot \mathrm{CaO} \cdot 3 \mathrm{SiO}_{2}\left(\mathrm{~N}_{2} \mathrm{CS}_{3}\right)$ and $\mathrm{Na}_{2} \mathrm{O} \cdot 2 \mathrm{CaO} \cdot 3 \mathrm{SiO}_{2}\left(\mathrm{NC}_{2} \mathrm{~S}_{3}\right)$ without any presence of iron (Figure 5).

$\mathrm{N}_{2} \mathrm{CS}_{3}$ melts incongruently [7] (melting starts at $1141{ }^{\circ} \mathrm{C}$ with creation of $78.5 \%$ of melt and $21.5 \%$ of $\mathrm{NC}_{2} \mathrm{~S}_{3}$, ends at $1203^{\circ} \mathrm{C}$ ). $\mathrm{NC}_{2} \mathrm{~S}_{3}$ melts congruently with an extensive field of primary crystallization. In the temperature range of Midrex process only two eutectics exist (Figure 6): $755{ }^{\circ} \mathrm{C}-\mathrm{N}_{3} \mathrm{~S}_{8}+\mathrm{NCS}_{5}$ $+\mathrm{S}\left(\mathrm{N}_{2} \mathrm{O}-22 \% ; \mathrm{CaO}-3.8 \% ; \mathrm{SiO}_{2}-74.2 \%\right) ; 827^{\circ} \mathrm{C}-\mathrm{N}_{2} \mathrm{CS}_{3}+\mathrm{NC}_{2} \mathrm{~S}_{3}+\mathrm{NS}_{2}\left(\mathrm{~N}_{2} \mathrm{O}-36.6 \% ; \mathrm{CaO}-1.8 \%\right.$; $\left.\mathrm{SiO}_{2}-60.7 \%\right)$.

In the phases detected by the X-ray spectral microprobe analysis, $\mathrm{CaO}$ content exceeds $10 \%$, indicating that limited melt formation takes place in these areas. Detected phase at temperatures in the range of $870-950^{\circ} \mathrm{C}$ can be in amorphous state with low amounts of liquid phases, as illustrated in Figure 7. 


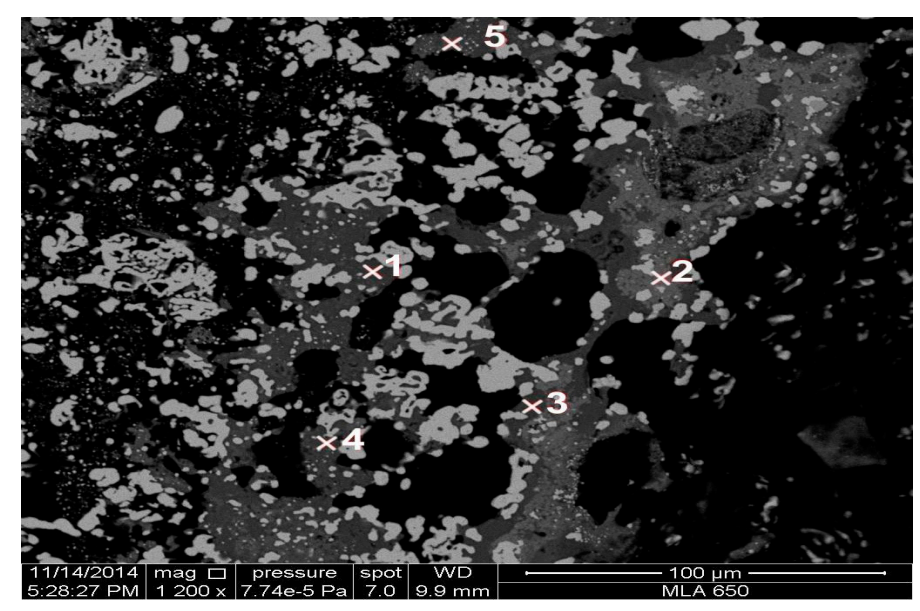

Figure 5. SEM-image of the reduced cement-bonded brex. 1, 3, 4-binary metasilicates; 2-silica containing calcium ferrite; 5-dicalcium ferrite.

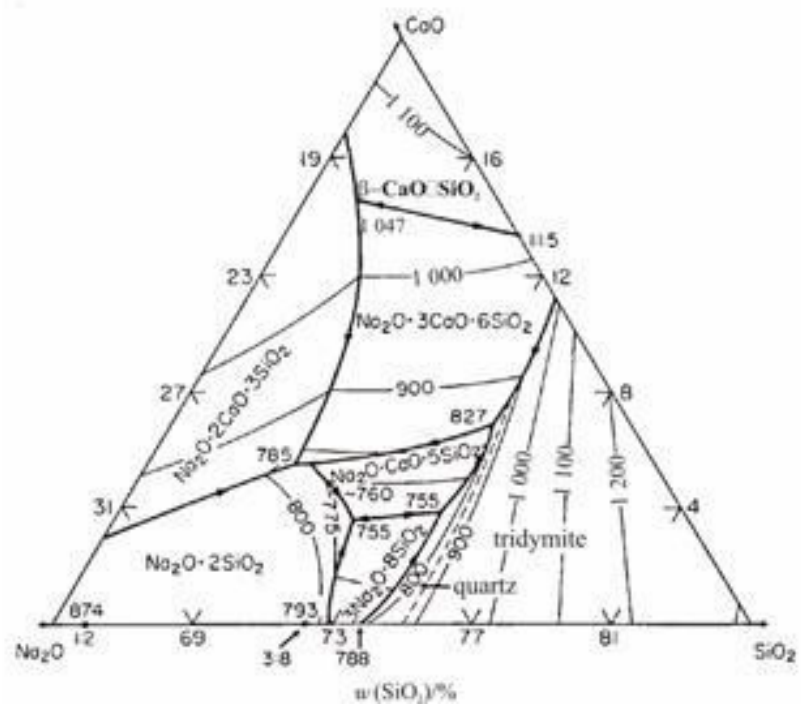

Figure 6. Diagram of the system $\mathrm{Na}_{2} \mathrm{O}-\mathrm{CaO}-\mathrm{SiO}_{2}$.

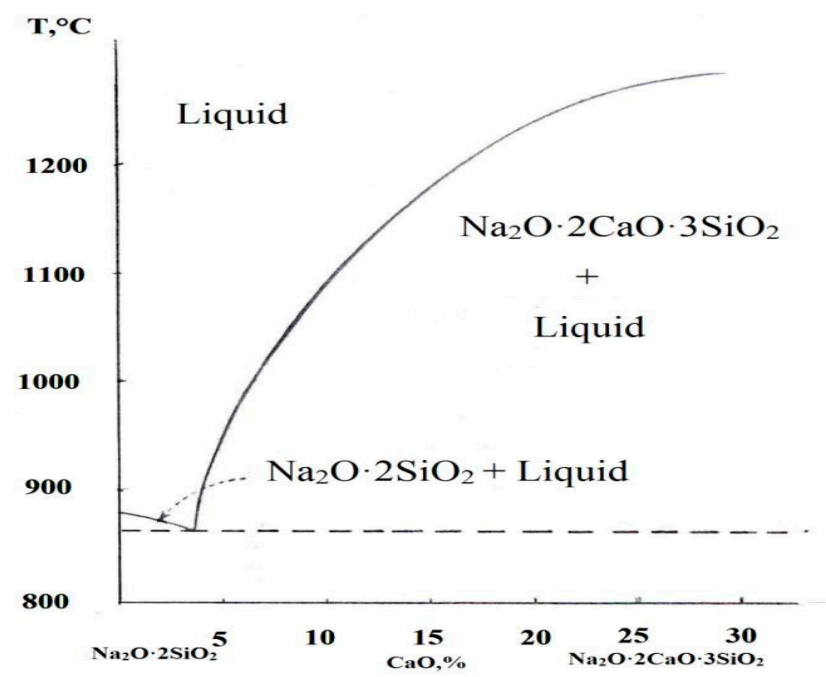

Figure 7. Diagram of system $\mathrm{Na}_{2} \mathrm{O} \cdot 2 \mathrm{SiO}_{2}-\mathrm{Na}_{2} \mathrm{O} \cdot 2 \mathrm{CaO} \cdot 3 \mathrm{SiO}_{2}$. 
In the cement-bonded brex, the alkali-silicate phase is dominantly associated with the smallest, dusty fractions which contain the alkali. The silicate bonding is not fully developed in the sample's body. Optical study of the samples of the reduced brex shows the pieces of crystals of dicalcium silicate $\left(\mathrm{Ca}_{2} \mathrm{SiO}_{4}\right)$.

\subsubsection{Mineralogical Analysis of the Reduced Lime-Bonded Brex}

Lime-bonded brex have higher degree of metallization and deeper interaction between charge components. Such samples are characterized by variation of the composition of iron-silicate melts in different parts of the body of brex. The most prevailing is the combination of the primary melt with iron. In this case, creation of melt is related to the enveloping of the pellets fines particles by the dust fractions. Primary iron-silicate melt composition is close to olivine phases. Melt has high basicity $\left(\mathrm{CaO} / \mathrm{SiO}_{2}=0.8-0.9\right), \mathrm{Na}_{2} \mathrm{O}$ content in different parts of the sample ranges from $1.0 \%$ to $10 \%$, magnesium and manganese oxides content does not exceed 1.0-2.0 mass \%. Under the conditions of Midrex process at the contacts of pellets fines with the melt, the metallic whiskers are being generated (Figure 8).

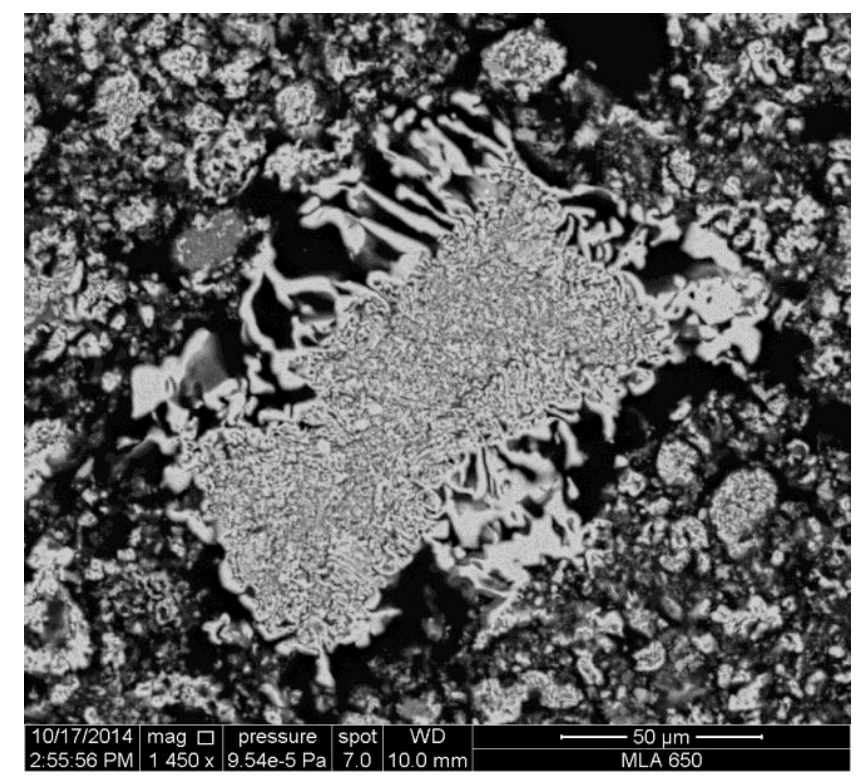

Figure 8. Generation of the metallic "whiskers" at the contacts of the pellets fines and melts.

Rarely in brex with lime as a binder the mineral formations with high content of calcium oxide (up to $40 \%$ ), silicon oxide content (25-26\%) and the same amounts of bivalent iron are observed. Any other oxides are not found in the composition of the amorphous iron-calcium phases with high calcium content. The composition of such phases is close to the Melilite phase $\left(\mathrm{Ca}_{2} \mathrm{Fe}_{3}+\mathrm{Si}_{2} \mathrm{O}_{7}\right)$.

The fine fraction dominating in the brex is of particular interest. It consists of a combination of metal with calcium ferrites. Apparently, in pellets fines, consisting of the combination of Hematite with calcium ferrite, Hematite phase was first to reduce and such reduction took place without breaking the contact with ferrite.

\subsubsection{Mineralogical Analysis of the Reduced Brex with Magnesium Sulfate-Based Binder}

Brex with magnesium sulfate binder exhibited the highest degree of metallization and well-developed process of the melt generation. We can compare these results with those obtained in the Midrex reactor of the ArcelorMittal in Hamburg with roller briquettes of the following composition: $37.6 \%$ DRI filter cake, $47 \%$ oxide fines, $9.4 \%$ return fines and $6 \%$ of hydrated lime and molasses as binders [8]. The total iron content in the raw briquettes amounted to $59 \%$, in the reduced- $77 \%$. Degree 
of metallization of the briquettes extracted from deformable steel packages was $86 \%$ [8]. Brex with magnesium sulfate-based binder revealed a greater degree of metallization $(96.71 \%)$ with a lower initial value of the total iron content $(62.61 \%)$ in the raw brex and with a smaller content of binder $(5 \%)$.

For the first time in this study it was found that, during the metallization, the original microstructure of brex does not persist. Brex is close to a two-phase system: metal and silicate phase. However, the composition of the silicate part remains non-uniform in the adjacent volumes of the reacted fines. According to X-ray spectral microprobe analysis, among the studied melts two mineral species are dominating-close to the olivine and Melilite structures, but each with different content of iron oxides, magnesium and manganese. This conclusion has been also confirmed by the results of the optical microscopy of the brex samples (Figure 9).

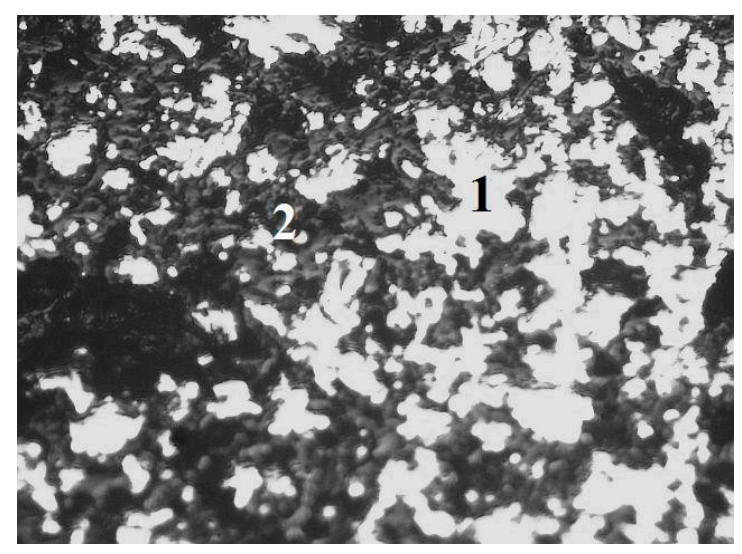

Figure 9. Optical microscopy of the reduced lime-bonded brex (1-iron, 2-Mellilite; magnification 200).

The areas of the melt which have reached equilibrium are of particular interest. Mineral phase in combination with residual melt is observed in these areas (Figure 10).

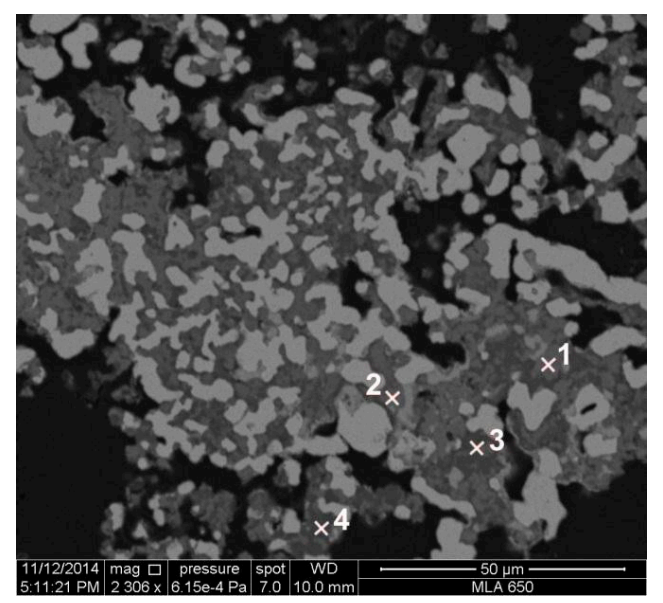

Figure 10. Structure of the reduced brex (1,2-mineral phase; 3, 4-residual melt).

Thus, it is clear that the mechanism of brex samples strengthening in each case has its own specific characteristics. For cement-bonded brex, lack of hot strength during heating in the reducing atmosphere is associated with their swelling and with the limited formation of silicate bonding. The strength of lime-bonded brex during reduction process is ensured by formation in the solid phase of the iron-calcium silicates, similar in composition to the olivine phase with low melting temperature. Brex with the magnesium sulfate-based binder has the highest degree of generation of the two-phase 
metal-silicate system at the end of the metallization process but the sulfur content does not allow their utilization in the charge of Midrex reactor.

\subsection{Morphological Study of the Porosity Change during Reduction}

During the process of reduction of the brex placed in deformable steel packages their porosity changed differently. With the aim of studying the nature of such changes, we have investigated the structure of the porosity of the original and reduced brex. Microstructure of samples was studied using scanning electronic microscope (SEM) 1450 LEO VP (Carl Zeiss, Jena, Germany) with resolution $3.5 \mathrm{~nm}$. For morphological studies of microstructure of the samples the secondary electrons mode has been used, which allows to obtain high-quality halftone images in a wide range of magnifications. Quantitative analysis of microstructure was conducted using software STIMAN [9] by two different methods: first-based on a series of SEM images obtained in back-scattered electrons, which allows to receive the correct picture with clearer boundaries between the pores and particles; second-by complex analysis based on a set of SEM image and images captured using computer tomography Yamato TDM-1000 (Yamato Scientific, Tokyo, Japan). Results of morphological studies are given in Table 6.

Table 6. Morphological parameters of the original and reduced brex *.

\begin{tabular}{|c|c|c|c|c|c|c|c|}
\hline \multirow{3}{*}{ BREX } & \multirow{3}{*}{$\begin{array}{c}\text { Porosity } \\
\text { SEM/SEM + CT } \\
p_{\text {tot }}, \%\end{array}$} & \multicolumn{5}{|c|}{$\begin{array}{c}\text { Contribution of Pores of Different Dimension Categories } \\
\text { to Total Porosity }\left(\mathrm{p}_{\text {tot }}\right), \% \text {. Diameter in Microns. }\end{array}$} & \multirow{2}{*}{$\begin{array}{c}\text { Maximum } \\
\text { Diameter, } \mu \mathrm{m}\end{array}$} \\
\hline & & $D_{1}$ & $D_{2}$ & $\mathrm{D}_{3}$ & $\mathrm{D}_{4}$ & $\mathrm{D}_{5}$ & \\
\hline & & $<0.1$ & $0.1-1.0$ & $1.0-10$ & $10-100$ & $>100$ & \\
\hline \multirow{2}{*}{ Brex \#1 } & 31.6 & 0.6 & 8.6 & 25.6 & 65.2 & 0.0 & 57.6 \\
\hline & 37.3 & 0.5 & 7.2 & 21.4 & 66.8 & 4.1 & 407.2 \\
\hline \multirow{2}{*}{$\begin{array}{l}\text { Brex \#1 } \\
\text { (reduced) }\end{array}$} & 32.9 & 0.2 & 9.0 & 38.4 & 52.4 & 0.0 & 70.94 \\
\hline & 38.3 & 0.1 & 7.7 & 32.4 & 49.8 & 10.0 & 504.49 \\
\hline \multirow{2}{*}{ Brex \#2 } & 31.2 & 0.6 & 8.0 & 30.1 & 61.3 & 0.0 & 45.78 \\
\hline & 35.7 & 0.5 & 7.0 & 26.2 & 61.3 & 5.0 & 299.96 \\
\hline \multirow{2}{*}{$\begin{array}{l}\text { Brex \#2 } \\
\text { (reduced) }\end{array}$} & 37.9 & 0.2 & 9.3 & 31.1 & 59.1 & 0.3 & 100.51 \\
\hline & 40.4 & 0.2 & 8.9 & 29.5 & 55.2 & 6.2 & 583.77 \\
\hline \multirow{2}{*}{ Brex \#3 } & 31.8 & 0.6 & 5.8 & 28.4 & 65.2 & 0.0 & 62.92 \\
\hline & 32.9 & 0.5 & 5.5 & 27.2 & 65.3 & 1.5 & 191.89 \\
\hline \multirow{2}{*}{$\begin{array}{l}\text { Brex \#3 } \\
\text { (reduced) }\end{array}$} & 32.8 & 0.2 & 3.2 & 35.7 & 60.9 & 0.0 & 71.75 \\
\hline & 39.3 & 0.2 & 2.6 & 28.9 & 58.0 & 10.3 & 736.41 \\
\hline
\end{tabular}

During the process of metallization, total porosity of brex with magnesium sulfate binder increased by $19.5 \%$, cement-bonded brex by $13.15 \%$ and brex with lime as a binder only by $2.6 \%$. The porosity increased due to large and mega pores (larger than $100 \mu \mathrm{m}$ ): for brex with magnesium sulfate binder-in 6.9 times, for lime-bonded brex-in 2.43 times. In cement-bonded brex, growth of large pores share was 1.24 times. Maximum diameter of pores in brex with magnesium sulfate binder has increased almost in three times and in brex with the lime-in 1.23 times. The difference in the nature of changes of porosity between original and reduced brex can also be clearly seen on images captured by computer tomography (Figure 11). In brex with magnesium sulfate- and lime-based binders, the development of internal cracks took place. This contributed to the formation of coherent porous systems and to the increase in the reduction rate. 


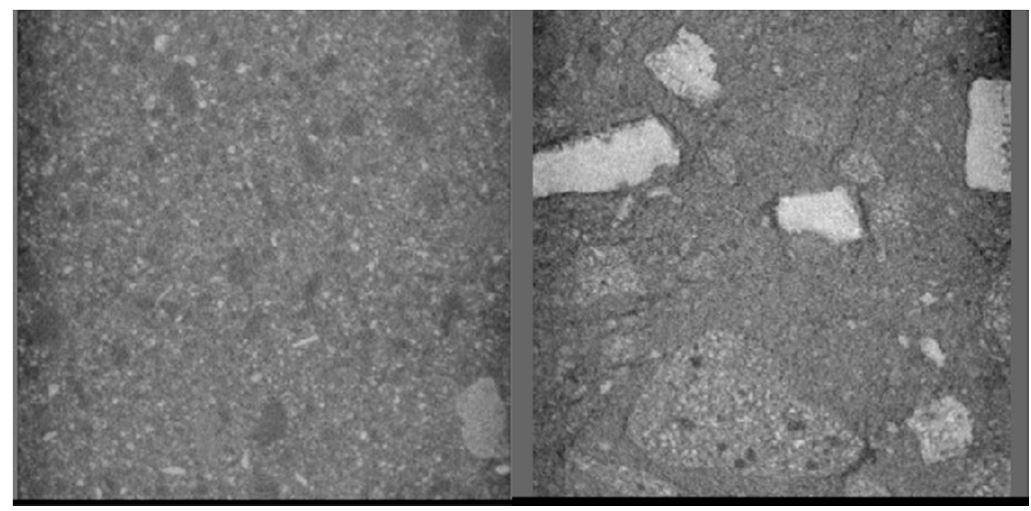

(a)

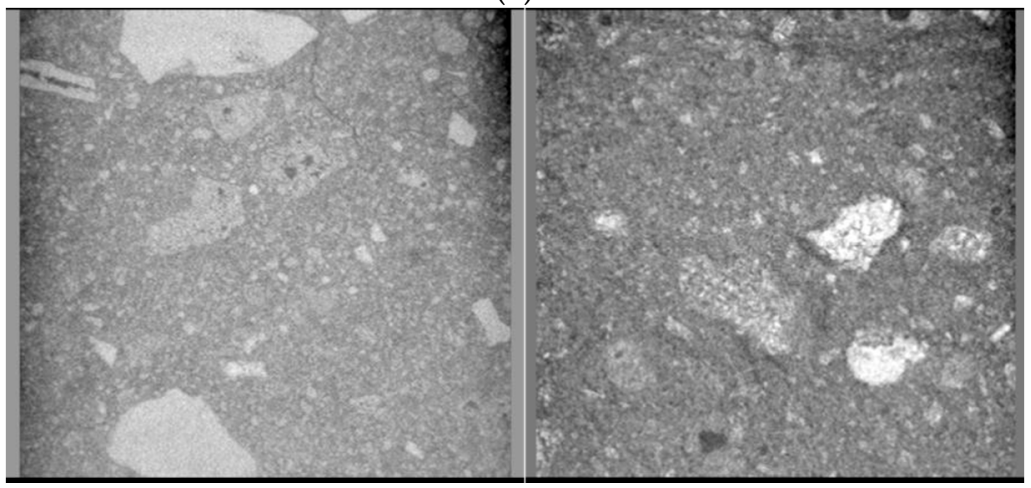

(b)

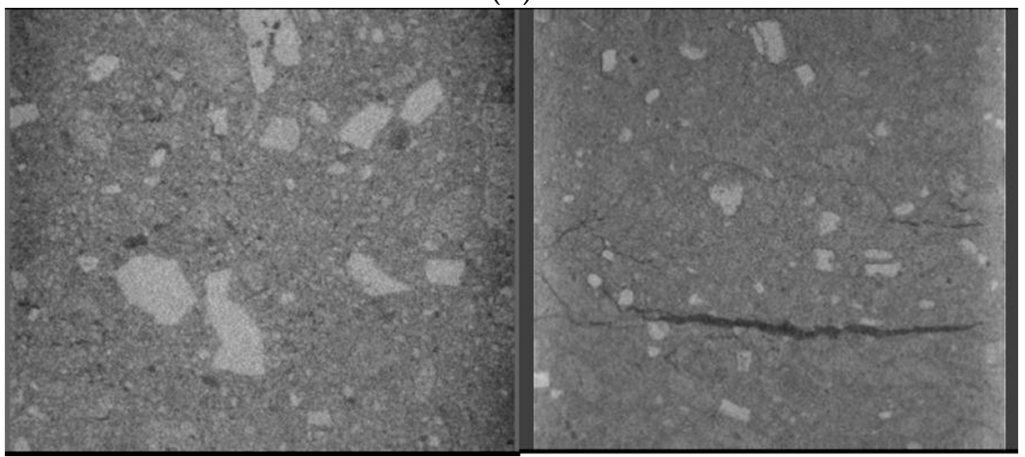

(c)

Figure 11. Distribution of pores in the original (left) and reduced (right) brex; (a) lime-bonded; (b) cement-bonded brex; (c) brex with magnesium sulfate based binder, magnification 64 .

It can be assumed that the driving mechanism for the development of porosity in the brex were the crystal lattice type changes during phase transformations Hematite-magnetite, which results in the increase of brex volume. This increase in volume is accompanied by mechanical stresses, which may lead to the partial destruction of brex which leads to an increase in the proportion of large and mega-pores and to the formation of internal cracks. The stronger the brex is mechanically, the less it is prone to such partial destruction.

\section{Conclusions}

The results of the full-scale testing of the brex produced by SVE agglomeration technology as the charge components of the industrial Midrex reactor can be summarized as follows:

- Reduction of the brex with cement as binder was accompanied by the formation of a significant amount of fines which retarded their metallization due to clogging of the holes in the walls of the steel packages, which resulted in a violation of the conditions of the experiment. 
- Low hot strength of brex with cement as a binder results from their tendency to swell as well as due to the low level of generation of silicate binders. It might be required to have cement content larger than $10 \%$ to avoid brex abnormal swelling and to promote for their sufficient hot strength.

- A sufficiently high value of the degree of metallization of the lime-bonded brex justifies further testing of such brex.

- Degree of metallization of the magnesium sulfate-bonded brex (96.71\%) is comparable with the degree of metallization of the main product of DRI reactors-metallized pellets.

- During the reduction, brex microstructure changes, becoming close to the metal-silicate phase.

- There is the difference in the porosity change during the reduction depending on the type of the binder applied. In brex with magnesium binder, process of metallization was accompanied by the growth of the large pores shares.

- High Sulphur content of the brex with magnesium sulfate-based binder makes them unsuitable for Midrex reactors.

Acknowledgments: The research has been done by authors independently.

Author Contributions: Research has been conceived and implemented by Aitber Bizhanov. Theoretical analysis of the results of mineralogical studies has been done by Aitber Bizhanov and Tatyana Malysheva.

Conflicts of Interest: The authors declare no conflict of interest.

\section{References}

1. Bizhanov, A.M.; Pavlov, A.V.; Chadaeva, O.; Dalmia, Y.; Mishra, B. High Temperature Reduction of the Stiff Vacuum Extrusion Briquettes under the ITmk3 Conditions. ISIJ Int. 2014, 54, 1450-1452. [CrossRef]

2. Bizhanov, A.M.; Kurunov, I.F.; Podgorodetskyi, G.; Dashevskyi, V.; Pavlov, A.V.; Chadaeva, O. Extruded Briquettes-New Charge Component for the Manganese Ferroalloys Production. ISIJ Int. 2014, 54, 2206-2214. [CrossRef]

3. Bizhanov, A.M.; Kurunov, I.F.; Dalmia, Y.; Mishra, B.; Mishra, S. Blast Furnace Operation with $100 \%$ Extruded Briquettes Charge. ISIJ Int. 2015, 55, 175-182. [CrossRef]

4. Zhuravlev, V.F.; Zhitomirskaya, V.I. Binding properties of crystal hydrates of the sulfate type. J. Appl. Chem. USSR 1950, 23, 115-119.

5. Bizhanov, A.M.; Kurunov, I.F.; Wakeel, A.K. Behavior of Extrusion Briquettes (Brex) in Midrex Reactors. Part 1. Metallurgist 2015, 59, 3-4. [CrossRef]

6. Singh, M.; Bjorkman, B. Cold bond agglomerates of iron and steel plant by-products as burden material for blast furnaces. In Proceedings of the REWAS 99, San Sebastian, Spain, 5-9 September 1999; Volume 2, pp. 1539-1548.

7. Berezhnoy, A.S. Multi Alkaline Oxide Systems; Naukova Dumka: Kiev, Ukraine, 1988; p. 200.

8. Schwelberger, J.; Brunner, C.; Fleischanderl, A. Recycling of Ferrous By-Products in the Iron and Steel. In Proceedings of the 34th Biennale Conference of the Institute for Briquetting and Agglomeration, Scottsdale, AZ, USA, 8-11 November 2015.

9. Sokolov, V.N.; Yurkovets, D.I.; Melnik, V.N.; Boyde, A.; Howell, P.G.T. 3D reconstruction of surface and subsurface structures of solids by SEM stereo images. In Proceedings of the Institute of Physics Electron Microscopy and Analysis Group Conference, Dundee, Scotland, UK, 5-7 September 2001. 